\title{
Curtobacterium flaccumfaciens pv. flaccumfaciens: etiologia, detecção e medidas de controle
}

\author{
Giseli Valentini \\ Altamir Frederico Guidolin* \\ Joana Neres da Cruz Baldissera \\ Jefferson Luís Meirelles Coimbra \\ Instituto de Melhoramento e Genética Molecular \\ Centro de Ciências Agroveterinárias, Universidade do Estado de Santa Catarina \\ Av. Camões 2090, 88520-000, Lages-SC, Brasil \\ *Autor para correspondência \\ a2afg@cav.udesc.br
}

Submetido em 08/02/2010

Aceito para publicação em 01/09/2010

\section{Resumo}

As doenças de etiologia bacteriana são problemas fitopatológicos e agronômicos em várias culturas de interesse econômico. A Murcha de Curtobacterium causada pela Curtobacterium flaccumfaciens pv. flaccumfaciens tem se tornado uma ameaça ao cultivo do feijão (Phaseolus vulgaris L.). Sua constatação no território brasileiro ocorreu em 1995 e hoje o patógeno encontra-se distribuído em várias regiões produtoras de feijão do país. A transmissão ocorre principalmente via sementes contaminadas, o que impõe grandes dificuldades e limitações para a contenção desta bactéria, sendo a erradicação das plantas a única forma de controle pósinfecção. As alternativas viáveis para o controle desta doença são: a utilização de sementes sadias, a rotação de culturas e o uso de variedades resistentes, sendo este último, um dos métodos mais eficiente e economicamente viável para o produtor. Estudos têm sido desenvolvidos para dar suporte ao desenvolvimento de cultivares resistentes à bactéria $C$. flaccumfaciens pv. flaccumfaciens, dentre os quais destacam-se a identificação de fontes de resistência genética à bactéria e o estudo dos mecanismos de herança genética da resistência à doença.

Unitermos: bacteriose, Murcha de Curtobacterium, Phaseolus vulgaris L.

\section{Abstract}

Curtobacterium flaccumfaciens pv. flaccumfaciens: etiology, detection and control strategies. The diseases caused by bacteria present a phytopathological and agricultural problem in various economic crops. The Curtobacterium wilt caused by Curtobacterium flaccumfaciens pv. flaccumfaciens has become a threat to the cultivation of beans (Phaseolus vulgaris L.). The disease statement for the Brazilian territory occurred in 1995 and today the pathogen is distributed in various Brazilian producing regions. Transmission is primarily via contaminated seed, which imposes great difficulties and limitations on the control of these bacteria. After plant infection, the only way to control it is the eradication of infected plants. The alternatives for the control of this disease are the use of healthy seeds, crop rotation and resistant varieties. The use of resistant varieties is the most efficient and economical solution for the farmer. The most important research to support the development of bean cultivars resistant to $C$. flaccumfaciens pv. flaccumfaciens is the identification of sources of genetic resistance and the study of mechanisms of genetic resistance to disease.

Key words: bacteria, Curtobacterium wilt, Phaseolus vulgaris L. 


\section{Introdução}

Estudos revelam que a taxa de utilização de sementes de feijão fiscalizadas em Santa Catarina é de apenas 20\%, havendo prevalência do uso de sementes produzidas pelo próprio agricultor (Herbes et al., 2008). Já em Minas Gerais, apenas 10\% da área é cultivada com sementes fiscalizadas (Sena et al., 2008). Entre outros problemas, a falta do uso de sementes fiscalizadas ocasiona a disseminação de patógenos através das sementes contaminadas, pois estão associados a agentes fitopatogênicos, tanto fúngicos quanto bacterianos.

As doenças de etiologia bacteriana em plantas são problemas fitopatológicos e agronômicos sérios em qualquer parte do mundo e, especialmente, em países tropicais, por razões técnicas, climáticas, históricas, políticas e econômicas, como é o caso do Brasil (Romero, 2005), onde mesmo com todas as medidas de manejo adotadas, estima-se que ocorrem perdas de $15 \%$ no rendimento do feijão devido às doenças (Manten, 2008).

Entre os patógenos causadores de doenças bacterianas, que podem causar prejuízos ao feijão, estão Xanthomonas axonopodis pv. phaseolli, Pseudomonas savastanoi pv. phaseolicola e Curtobacterium flaccumfaciens pv. flaccumfaciens. Esta última bactéria, C. flaccumfaciens pv. flaccumfaciens (Hedges) (Collins e Jones, 1983) teve seu primeiro relado no estado de Dakota do Sul nos Estados Unidos da América, em 1920, conforme Hedges (1922). Em nosso país a doença foi constatada no ano de 1995 no estado de São Paulo (Maringoni e Rosa, 1997) e hoje se encontra distribuída em grande parte das principais regiões produtoras de feijão do Brasil. Em 2001, foi identificado seu aparecimento no estado de Goiás e Distrito Federal (Uesugi et al., 2003) e no estado de Santa Catarina o primeiro relato ocorreu no município de Campos Novos (Leite Junior et al., 2001). Mais recentemente a doença foi encontrada nos municípios de Faxinal dos Guedes, Guatambú, Ipuaçu, Ponte Serrada e Tigrinhos (Theodoro et al., 2004). A presença da Murcha de Curtobacterium nos vários municípios catarinenses citados por Theodoro et al. (2004) indica adaptabilidade do patógeno ao hospedeiro em diferentes ambientes, demonstrando a necessidade da adoção de medidas para seu controle. $\mathrm{O}$ feijão é cultivado durante todos os meses do ano e a sua produção provém de quase todo o território nacional, o que permite a sobrevivência do patógeno (Bertoldo et al., 2009).

Em função dessa expansão, várias pesquisas vêm sendo desenvolvidas a fim de identificar a presença ou não da fitobactéria em lavouras de feijão (Maringoni, 2002; Hsieh, 2005; Herbes et al., 2008), assim como a existência da resistência de cultivares e genótipos locais de feijão (Maringoni, 2002; Souza et al., 2006a; Theodoro et al., 2007).

O objetivo deste trabalho foi reunir informações sobre a Murcha de Curtobacterium do feijão, disponíveis na literatura especializada, visando o conhecimento da sua etiologia, detecção e medidas de controle do patógeno, que possam ser aplicados na prevenção de perdas na produtividade da cultura.

\section{Considerações gerais sobre o patógeno}

De acordo com Coelho et al. (2004), na ocasião da sua descrição, em 1922, a bactéria causadora da Murcha de Curtobacterium foi denominada Bacterium flaccumfaciens. Posteriormente recebeu as denominações: Phytomonas flaccumfaciens; Pseudomonas flaccumfaciens; Corynebacterium flaccumfaciens; Corynebacterium flaccumfaciens pv. flaccumfaciens; Corynebacterium flaccumfaciens subsp flaccumfaciens; e finalmente, baseando-se em estudos dos perfis de proteína celulares através de eletroforese em gel de poliacrilamida, a bactéria foi reclassificada dentro de um novo gênero Curtobacterium, denominando-se Curtobacterium flaccumfaciens pv. flaccumfaciens (Collins e Jones, 1983).

A bactéria C. flaccumfaciens pv. flaccumfaciens pertencente ao Domínio Bactéria, Filo Actinobacteria, Classe Actinobacteria, Subclasse Actinobacteride, Ordem Actinomycetales, Subordem Micrococcineae, Família Microbacteriaceae, caracterizada como bastonetes retos, ligeiramente curvos ou em forma de cunha e curtos $(0,3$ a 0,6 por 1 a $3 \mu \mathrm{m})$, móvel por um ou mais flagelos polares ou subpolares, gram positiva, aeróbia obrigatória e não forma endósporo. Em meio de cultura extrato de levedura-glicose-ágar, as bactérias 
apresentam colônias ligeiramente convexas, sem viscosidade, semifluidas e de coloração amarela, laranja ou vermelha, podendo também produzir um pigmento solúvel em água de coloração azul ou púrpura (Davis e Vidaver, 2001). Além disso, desenvolve-se bem em temperaturas ótimas de 24 a $37^{\circ} \mathrm{C}$, com temperaturas máximas entre 35 a $37^{\circ} \mathrm{C}$ e apresenta tolerância a presença de sal, com 7\% a 9\% de $\mathrm{NaCl}$ (Bradbury, 1986).

Isolados da bactéria, cujas colônias se apresentam com coloração amarela, laranja e vermelha de $C$. flaccumfaciens pv. Flaccumfaciens, testadas em cultivares e linhagens, apresentaram uma reação similar para ambas as variações de coloração do patógeno amarelo e laranja (Hsieh et al., 2005). Em outra situação, o germoplasma resistente ao isolado de coloração vermelha também foi resistente às amarelas e às laranjas (Huang et al., 2007a). A existência de germoplasma resistente às três variedades da bactéria é um importante recurso para o desenvolvimento de novas cultivares de feijão.

Porém, há indicação de existência de ampla diversidade genética entre isolados de C. flaccumfaciens pv. flaccumfaciens, conforme demonstram Souza et al. (2006b) avaliando 26 isolados e Wendland et al. (2008) avaliando sete isolados. A possibilidade da existência de variabilidade genética em isolados pode ser uma consequência maléfica ao melhoramento visando à obtenção de cultivares de feijão resistentes, especialmente na estabilidade e durabilidade da resistência.

\section{Detecção de Curtobacterium flac- cumfaciens pv. flaccumfaciens em se- mentes}

O uso de métodos de detecção de patógenos em sementes é indispensável, uma vez que as sementes constituem a principal fonte de inóculo no campo e podem ser transportadas a longas distâncias. As avaliações de sanidade, visando à identificação de patógenos e descarte dos lotes contaminados, asseguram a sanidade dos lotes a serem comercializados e assim, evitar a ocorrência de epidemias generalizadas.
Técnicas moleculares estão sendo utilizadas em estudos de variabilidade genética, identificação e caracterização de isolados bacterianos. Tegli et al. (2002) identificaram os iniciadores CffFOR2 e CffREV4, os quais foram eficientes na detecção de C. flaccumfaciens pv. flaccumfaciens em sementes de feijão. Também utilizando a técnica PCR, Guimarães et al. (2001) mostram que iniciadores CF4 e CF5 são altamente específicos para o patógeno de C. flaccumfaciens pv. flaccumfaciens, com nenhuma reação cruzada com outras bactérias testadas. Em amostras ambientais de solo e restos de cultura de feijão Nunes et al. (2004) demonstraram que os primers selecionados são específicos e eficientes para utilização na identificação e detecção da bactéria, demonstrando que PCR representa uma ferramenta importante para programas de melhoramento e fitossanidade na cultura do feijão.

Os meios de cultura semi-seletivos permitem recuperar e identificar as populações bacterianas em sementes, bem como em solos e restos culturais. Maringoni e Câmara (2006) utilizaram meio de cultura semi-seletivo para detectar C. flaccumfaciens pv. flaccumfaciens, em trinta amostras de sementes de feijão infectadas naturalmente, e verificaram a eficiência do uso do meio de cultura semi-seletivo para identificar a presença da bactéria em cinquenta por cento das amostras de sementes analisadas. Adaptações do meio CNS (Corynebacterium Nebraskense Selective Medium) foram propostas com a finalidade de detectar C. flaccumfaciens pv. flaccumfaciens em solo e sementes contaminadas (Behlau et al., 2006). O meio CNS modificado é eficiente na recuperação das bactérias de amostras de solo e sementes contaminadas, e pode ser utilizado como uma ferramenta em estudos epidemiológicos e ecológicos da bactéria, assim como em análises fitossanitárias de sementes de feijão.

\section{Transmissão do patógeno}

A principal forma de transmissão da bactéria ocorre através de sementes contaminadas, as quais podem estar infectadas internamente ou apenas infestadas superficialmente. As sementes contaminadas internamente podem apresentar coloração amarelada, laranja ou púrpura, como consequência do crescimento bacteriano, e se 
tornarem enrugadas, no entanto, na maioria das vezes nenhum sintoma é visível. A sobrevivência do patógeno nas sementes e no solo pode ocorrer por dois anos ou por períodos mais longos, quando a semente é armazenada em condições ótimas (Tegli et al., 2002). Outros relatos apontam que a bactéria $C$. flaccumfaciens pv. flaccumfaciens sobrevive por 25 anos em sementes infectadas e estocadas em temperatura ambiente (Burkholder, 1945). De modo geral, patógenos de sementes possuem um longo período de sobrevivência em sementes. A bactéria Xanthomonas axonopodis pv. phaseoli pode sobreviver por períodos de até 5 anos em sementes de feijão, quando armazenada em condições adequadas, mantendo as populações bacterianas elevadas e com capacidade de causar doença em plântulas emergentes (Marques et al., 2005).

Bacterioses de plantas transmitidas por sementes são relatadas em várias culturas de importância econômica: Corrêa et al. (2008) cita Xanthomonas vesicatoria em sementes de tomateiro; Romeiro et al. (1993a) em sementes de cebola, demonstraram a transmissão de Pseudomonas gladioli pv. alliicola; Romeiro et al. (1993b) estudaram a porcentagem de transmissão de Xanthomonas campestris pv. phaseolli em sementes de feijão.

No Brasil, a maioria das enfermidades de plantas, que causam problemas, provavelmente, foi introduzida via sementes ou partes vegetativas trazidas das mais diversas regiões produtoras, como certamente é o caso da Murcha de Curtobacterium. Exemplo mai recente é a introdução no país de Agrobacterium vitis, que provoca a Galha da Videira, possivelmente introduzida através de mudas ou partes vegetativas trazidas de Israel. No Vale do Rio São Francisco, a introdução de mudas clandestinas de videira da Índia ou da África do Sul, resultou na introdução de Xanthomonas campestris pv. viticola. A bacteriose da mandioca causada por Xanthomonas axonopodis pv. manihotis, foi descrita no Brasil e atualmente encontra-se disseminada em todas as regiões produtoras do mundo (Romero, 2005).

\section{Sintomas manifestados pela planta infectada}

Os sintomas da doença nas lavouras geralmente aparecem em reboleiras, embora plantas isoladas possam ser encontradas. A bactéria ataca todas as partes da planta acima do solo, podendo levá-la a morte na fase inicial ou reduzir o crescimento, resultando em queda na produtividade da planta. Em condições ambientais favoráveis à doença, as plantas adultas infectadas apresentam folhas murchas, porém em condições menos favoráveis, a diagnose é dificultada, pois a murcha ocorre lentamente até a fase de maturação dos grãos. A murcha é a principal característica da doença, sendo o resultado da degeneração dos vasos do xilema pelas bactérias, que promove falha no transporte de seiva, deixando o caule internamente escurecido, seguida de amarelecimento e flacidez da área foliar, com posterior seca do tecido (Hedges, 1926). Os sintomas de escurecimento vascular, conjuntamente com os sintomas de murcha, se assemelham aos sintomas da Murcha de Fusarium, causado pelo fungo Fusarium oxisporum f. sp. phaseoli, motivo este que promove uma confusão na detecção da doença a campo. A semelhança entre os sintomas da Murcha de Curtobacterium e a Murcha de Fusarium provavelmente é um motivo que atrasou a constatação da doença no território brasileiro (Uesugi et al., 2003).

Exames detalhados de fragmentos do caule de genótipos de feijão suscetíveis a $C$. flaccumfaciens pv. flaccumfaciens através de microscopia eletrônica de varredura, constata a presença de grande quantidade de células bacterianas colonizando as pontuações das paredes dos vasos do xilema. Em plantas resistentes, vários aglomerados de células bacterianas foram encontrados, porém, anterior a formação desses aglomerados bacterianos, verificou-se a formação de uma rede filamentosa sobre a superfície das células bacterianas. Esses filamentos, inicialmente formavam ligações entre células próximas e distantes na região do xilema, diminuindo as distâncias entre as bactérias e formando as aglutinações. Este seria o provável motivo pelo qual o deslocamento das bactérias para outras regiões do vaso do xilema a partir do ponto de inoculação é dificultado. Concomitantemente a essas aglutinações, foi observado o crescimento de estrutura rendilhada sob as pontuações das paredes do xilema que, aparentemente, impossibilita o avanço e proliferação da bactéria para regiões adjacentes, dificultando o crescimento da população bacteriana. As projeções protoplasmáticas para o interior dos vasos de xilema em genótipos de 
feijão resistentes a $C$. flaccumfaciens pv. flaccumfaciens sugere o início da formação de tilose, ou seja, projeções que se entrelaçam e formam as estruturas rendilhada (Maringoni, 2002; Souza et al., 2006a). Tais observações levaram os autores a sugerir a atuação de mecanismo de resistência física e bioquímica em genótipos de feijão resistentes, estruturas estas não verificadas em genótipos suscetíveis. A presença de grande quantidade de células bacterianas nos vasos de xilema, em genótipos de feijão suscetíveis a C. flaccumfaciens pv. flaccumfaciens, ocasiona bloqueio no transporte da água, em consequência disto resultam os sintomas de murcha, amarelecimento, subdesenvolvimento e morte de plantas (Souza e Maringoni, 2008).

\section{Estratégias de controle da Murcha de Curtobacterium}

A Murcha de Curtobacterium, na ocasião da sua descoberta, em 1920, causava morte em cerca de $90 \%$ das plantas (Hedges, 1922). Nos anos subsequentes foi considerada como uma das principais doenças da cultura do feijão, ocasionando em alguns anos, perda total de produção (Hedges, 1926).

O controle desta fitobactéria está fundamentado no uso de cultivares resistentes, rotação de culturas e uso de sementes sadias (Maringoni e Camara, 2006; Alencar et al., 2008; Herbes et al., 2008) uma vez que o controle químico não é uma opção presente, pois não há produtos registrados para a bactéria. Após o surgimento na lavoura, o controle de bactérias em plantas infectadas é possível exclusivamente com a erradicação da cultura (Romero, 2005).

Entretanto, algumas precauções podem ser tomadas para minimizar a intensidade da manifestação da doença. Adequado manejo da cultura, que inclui o estado nutricional das plantas é um fator que pode ser manipulado visando melhores resultados. Todos os nutrientes minerais essenciais são importantes em relação a incidência ou severidade das doenças de plantas, para tanto é necessária adubação adequada de acordo com a análise de solo (Maringoni, 2003; Theodoro e Maringoni, 2006). A utilização do tratamento de sementes com Rhizobium leguminosarum para o controle da Murcha de Curtobacterium é uma possibilidade em discussão. As sementes de feijão inoculadas com C. flaccumfaciens pv. flaccumfaciens e tratados com agentes de controle biológico resultou em redução da incidência e severidade da Murcha de Curtobacterium e aumento na emergência das plântulas, assim como em sua altura (Huang et al., 2007b).

A utilização do tratamento térmico na erradicação de C. flaccumfaciens pv. flaccumfaciens pode ser uma alternativa para o controle da bactéria em sementes de feijão. Sementes embebidas por $2 \mathrm{~h}$ em água e tratadas por $3 \mathrm{~h}$ a uma temperatura de $60^{\circ} \mathrm{C}$ reduziram significativamente o número de células bacterianas em sementes de feijão. Do ponto de vista ambiental, é um método não poluente ou sem efeito residual e pode ser recomendado para erradicação do patógeno (Estefani et al., 2007).

O uso de cultivares resistentes é considerado um meio eficiente para uma série de doenças de plantas cultivadas, o que não vem ocorrendo na cultura do feijão, por exemplo, para o Crestamento Bacteriano Comum (Xanthomonas campestris pv. phaseoli), cujo controle é possível através de cultivares resistentes, especialmente quando incorporados em um sistema de gestão integrada da doença que promove o uso de sementes certificadas e rotação de cultura (Ferreira et al., 2003). Experiências com a utilização de produtos químicos não têm apresentado resultados satisfatórios no controle da bacteriose em condições de campo e o uso de cultivares resistentes ao crestamento bacteriano comum é limitado, pois não há no mercado cultivares de feijão com tal resistência. A natureza complexa da resistência, o grande efeito ambiental sobre o desenvolvimento dos sintomas e a baixa herdabilidade, faz com que o desenvolvimento de cultivares resistentes seja limitado (Mutlu et al., 2005; Vale et al., 2009).

A exemplo do Crestamento Bacteriano Comum é importante o desenvolvimento de cultivares resistentes à Murcha de Curtobacterium, sendo o conhecimento do tipo de herança genética da resistência ao patógeno o primeiro passo para alcançar o objetivo desejado. Estudos genéticos da resistência de feijão à Murcha de Curtobacterium apontam natureza poligênica da herança, no entanto pesquisas mais aprofundadas são 
necessárias para de fato, conhecer os componentes de variância envolvidos na segregação (Coyne et al., 1965).

Para atender a necessidade por genótipos resistentes ao patógeno, é de interesse do melhorista e fundamental para o avanço de um programa de melhoramento vegetal, a identificação de genótipos de feijão com bons níveis de resistência, o que facilita consideravelmente a incorporação desses genes em genótipos suscetíveis com potencial produtivo (Maringoni, 2002; Souza et al., 2006a; Theodoro et al., 2007).

Avaliações em torno da resistência ou tolerância de cultivares têm sido realizadas, no entanto, apenas alguns genótipos contém genes de resistência a Murcha de Curtobacterium. Trabalhos desenvolvidos por Maringoni (2002) avaliando quarenta cultivares de feijão e dois isolados evidenciaram a presença de resistência a Murcha de Curtobacterium apenas nas cultivares IAC Carioca Akytã, IAC Carioca Aruã e IAC Carioca Pyatã.

Trabalhos vêm sendo desenvolvidos a fim de identificar em genótipos locais, fontes de resistência à Murcha de Curtobacterium (Souza et al., 2006a; Theodoro et al., 2007). Genótipos cultivados por agricultores são excelentes fontes de variabilidade, pois são genótipos submetidos à pressão de seleção por vários anos, além de serem adaptados às condições de cultivo (Ramalho et al., 1993). Na literatura nacional, há indicação de linhagens locais de feijão resistentes à Murcha de Curtobacterium, sendo conhecidos Mouro Piratuba e Vagem Amarela, cultivares locais de feijão coletados no estado de Santa Catarina, pertencentes ao banco ativo de germoplasma da Epagri (Theodoro et al., 2007). Souza et al. (2006a) avaliaram 333 acessos pertencentes ao banco de germoplasma de feijão do Instituto Agronômico de Campinas (IAC), destes, 8,7\% comportaram-se como altamente resistentes, 3,9\% dos genótipos como resistentes e 5\% como moderadamente resistentes. Rava et al. (2003) também avaliaram 333 acessos de feijão provenientes de coletas efetuadas na Bahia, Espírito Santo, Minas Gerais, Goiás, Paraná, Santa Catarina e Rio Grande do Sul, encontrou cinco linhagens resistentes à bactéria, representando $1,5 \%$ dos acessos avaliados. Outros autores como Costa et al. (2008) relatam dificuldades para a obtenção de fontes de resistência a Murcha de Curtobacterium, pois entre 61 genótipos testados, apenas uma linhagem demonstrou resistência. A partir destes resultados, vários genótipos poderão ser úteis para programas de melhoramento genético como fonte de genes para resistência a Murcha de Curtobacterium.

Baseado no conhecimento já obtido sobre $C$. flaccumfaciens pv. flaccumfaciens e no que têm sido realizado para outras bactérias fitopatogênicas, algumas recomendações de manejo podem ser feitas, possibilitando redução na disseminação do patógeno e nos danos causados na cultura do feijão. Por conseguinte, alternativas viáveis são a utilização de rotação de culturas, o uso de sementes sadias e certificadas e uso de cultivares resistentes, sendo que hoje estão disponíveis as cultivares IAC Carioca Akytã, IAC Carioca Aruã e IAC Carioca Pyatã.

Tratando-se de um patógeno recentemente encontrado no Brasil e posteriormente detectado em várias regiões produtoras de feijão, medidas para evitar a disseminação do patógenos para outras localidades são indispensáveis, bem como pesquisas para aplicar o conhecimento já obtido sobre a doença e a utilização do material genético resistente disponível, para assim, abranger os estudos em outras áreas, focando no conhecimento dos mecanismos envolvidos na herança genética da resistência e desenvolvimento de cultivares resistentes.

\section{Referências}

Alencar, N. E.; Wendland, A.; Melo, L. C.; Costa, J. G. C.; Del Peloso, M. J.; Pereira, H. S.; Faria., L. C.; Côrtes, M. V. C. B. 2008. Avaliação fenotípica de genótipos de feijoeiro comum a isolados de Curtobacterium flaccumfaciens pv. flaccumfaciens. Anais do Congresso Nacional de Pesquisa de Feijão, Campinas Brasil, p.957-960.

Behlau, F.; Nunes, L. M., Leite Junior. R. P. 2006. Semi-selective medium for detection of Curtobacterium flaccumfaciens pv. flaccumfaciens in soil and on bean seeds. Summa Phytopathologica, 2 (4): 394-396.

Bertoldo, J. G.; Coimbra, J. L. M.; Guidolin, A. F.; Rocha, F. 2009. Tempo de cocção de grãos de feijão em função de doses de fósforo no plantio e do tempo de armazenamento. Revista Biotemas, 22 (1): 39-47.

Bradbury, J. F. 1986. Guide to plant pathogenic bacteria. Farhan House: C.A.B. International, Oxfordshire, UK, 332pp.

Burkholder, W. H. 1945. The longevity of the pathogen causing the wilt of the common bean. Phytopathology, 35: 743-744. 
Coelho, M. V. S.; Guimarães, P. M.; Marques, A. S. A.; Martins, O. M. 2004. Curtobacterium flaccumfaciens pv. flaccumfaciens, murcha bacteriana do feijoeiro e da soja: alto risco de disseminação no Brasil. Embrapa, Brasília, Brasil, 9pp. (Comunicado técnico, 117).

Collins, M. D.; Jones, D. 1983. Reclassification of Corynebacterium flaccumfaciens, Corynebacterium betae, Corynebacterium oortii and Corynebacterium poinsettiae in the genus Curtobacterium, as Curtobacterium flaccumfaciens comb. Nov. Journal of General Microbiology, 129: 3545-3548.

Costa, J. G. C.; Rava, C. A.; Puríssimo, J. D.; Peloso, M. J. D.; Melo, L. C.; Faria, L. C. 2008. Reação de genótipos de feijoeiro comum ao crestamento bacteriano comum e à murcha de curtobacterium. Revista Ceres, 55 (5): 93-395.

Corrêa, F. M.; Carvalho, A. O.; Carmo, M. G. F. 2008. Inoculação e sobrevivência de Xanthomonas vesicatoria em sementes de tomateiro. Summa Phytopathologica, 34 (1): 71-75.

Coyne, D. P.; Schuster, M. L.; Young, J. O. 1965. A genetic study of bacterial wilt (Corynebacterium flaccumfaciens var. aurantiacum) tolerance in Phaseolus vulgaris crosses and the development of tolerance to two bacterial diseases in beans. Journal of the American Society for Horticultural Science, 87: 279-85.

Davis, M. J.; Vidaver, A. K. 2001. Coryneform plant pathogens. In: Schaad, N. W., Jones, J. B., Chun, W. (Ed.). Plant pathogenic bacteria. $3^{\text {rd }}$ ed. APS Press, St. Paul, USA, p.218-235.

Estefani, R. C. C.; Miranda Filho, R. J.; Uesugi, C. H. 2007. Tratamentos térmico e químico de sementes de feijoeiro: eficiência na erradicação de Curtobacterium flaccumfaciens pv. flaccumfaciens e efeitos na qualidade fisiológica das sementes. Fitopatologia Brasileira 32: 434-438.

Ferreira, C. F.; Pereira, M. G.; Santos, A. S.; Rodrigues, R.; BressanSmith, R. E.; Viana, A. P.; Daher, R. F. 2003. Resistance to common bacterial blight in Phaseolus vulgaris L. recombinant inbred lines under natural infection of Xanthomonas axonopodis pv. phaseoli. Euphytica, 134: 43-46.

Guimarães, P. M.; Palmano, S.; Smith, J. J.; Sá, M. F. G.; Saddler, G. S. 2001. Development of a PCR test for the detection of Curtobacterium flaccumfaciens pv. flaccumfaciens. Antonie van Leeuwenhoek, 80 (1): 1-10.

Hedges, F. A. 1922. Bacterial wilt of bean caused by bacterial flaccumfaciens nov. sp. Science, 55 (1425): 433-434.

Hedges, F. A. 1926. Bacterial wilt of bean (bacterium flaccumfaciens hedges) including compartions with bacterium phaseoli. Phytopathology, 16 (1): 1-22.

Herbes, D. H.; Theodoro, G. F.; Maringoni, A. C.; Dal Piva, C. A.; Abreu, L. 2008. Detecção de Curtobacterium flaccumfaciens pv. flaccumfaciens em sementes de feijoeiro produzidas em Santa Catarina. Tropical Plant Pathology, 33 (2): 53-156.

Hsieh, T. F.; Huang, H. C.; Mündel, H. H.; Conner, R. L.; Erickson, R. S.; Balasubramanian, P. M. 2005. Resistence of common bean (Phaseolus vulgaris) to bacterial wilt caused by Curtobacterium flaccumfaciens pv. flaccumfaciens, Phytopathology, 153: 245-249.

Huang, H. C.; Erickson, R. S.; Hsieh, T. F. 2007b. Control of bacterial wilt of bean (Curtobacterium flaccumfaciens pv. flaccumfaciens) by seed treatment with Rhizobium leguminosarum. Crop Protection, 26: 1055-1061.

Huang, H. C.; Mündel, H.-H.; Erickson, R. S.; Chelle, C. D.; Balasubramanian, P. M.; Kiehn, F.; Conner, R. L. 2007a. Resistance of common bean (Phaseolus vulgaris L.) cultivars and germplasm lines to the purple variant of bacterial wilt (Curtobacterium flaccumfaciens pv. flaccumfaciens). Plant Pathology Bull, 16: 91-95.

Leite Júnior, R. P.; Meneguim, L.; Behlau, F.; Rodrigues, S. R.; Bianchini, A. 2001. Ocorrência de Curtobacterium flaccumfaciens pv. flaccumfaciens em feijoeiro no Paraná e Santa Catarina. Fitopatologia Brasileira, 2 (Suplemento): 303.

Manten, J. O. 2008. Importância de novos defensivos agrícolas no manejo de doenças no fejoeiro. Anais do Congresso Nacional de Pesquisa de Feijão, Campinas, Brasil, p.957-960.

Maringoni, A. C. 2002. Comportamento de cultivares de feijoeiro comum à murcha-de-curtobacterium. Fitopatologia Brasileira, 27: 157-162.

Maringoni, A. C. 2003. Alterações nos teores de macronutrientes em plantas de feijoeiro infectadas por Curtobacterium flaccumfaciens pv. flaccumfaciens. Ciência e Agrotecnologia, 27 (1): 217-222.

Maringoni, A. C.; Camara, R. C. 2006. Curtobacterium flaccumfaciens pv. flaccumfaciens detection in bean seeds using a semi-selective culture medium. Brazilian Journal of Microbiology, 37: 451-455.

Maringoni, A. C.; Rosa, E. F. 1997. Ocorrência de Curtobacterium flaccumfaciens pv. flaccumfaciens em feijoeiro no Estado de São Paulo. Summa Phytopathologica, 23: 160-162.

Marques, A. S. A; Guimaraes, P. M; Santos, J. P; Vieira, T. M. 2005. Sobrevivência e viabilidade de Xanthomonas axonopodis pv. phaseoli em sementes de feijão armazenadas sob condições controladas. Fitopatologia Brasileira, 30 (5): 527-531.

Mutlu, N; Miklas, P; Reiser J; Coyne, D. 2005. Backcross breeding for improved resistance to common bacterial blight in pinto bean (Phaseolus vulgaris L.). Plant Breeding, 124: 282-287.

Nunes, L. M.; Behlau, F.; Leite Júnior, R. P. 2004. Especificidade de primers para identificação e detecção de Curtobacterium flaccumfaciens pv. flaccumfaciens por PCR. Fitopatologia Brasileira, 29 (Suplemento): S43.

Ramalho, M. A. P.; Santos, J. B.; Zimmermann, M. J. O. 1993. Genética Quantitativa em Plantas Autógamas: Aplicações ao melhoramento do feijoeiro. Editora da UFG, Goiânia, Brasil, 271pp.

Rava, C. A.; Costa, J. G. C.; Fonseca, J. R.; Salgado, A. L. 2003. Fontes de resistência a antracnose, crestamento bacteriano comum e murcha de curtobacterium em coletas de feijoeito comum. Revista Ceres, 50 (292): 797-802.

Romeiro, R. S; Oliveira, J. R.; Melo, L. M. M. 1993a. Etiologia e transmissão pela semente de uma bacteriose da cebola. Revista Brasileira de Sementes, 15 (2): 221-226.

Romeiro, R. S.; Perez, F. S.; Oliveira, J. R.; Del Peloso, M. J. 1993b. Detecção de Xanthomonas campestris pv. phaseolli em sementes de feijoeiro. Revista Brasileira de Sementes, 15 (1): 1-5.

Romero, R. S. 2005. Bactérias fitopatogênicas. $2^{\mathrm{a} e d . ~ E d . ~ U F V, ~}$ Viçosa, Brasil, 417pp.

Sena, M. R.; Abreu, Â. F. B.; Ramalho, M. A. P.; Bruzi, A. T. 2008. Envolvimentoe de agricultores no processo seletivo de novas linhagens de feijoeiro. Ciência e Agrotecnologia, 32 (2): 407-412.

Souza, V. L.; Maringoni, A. C.; Krause-Sakate, R. 2006 b. Variabilidade genética em isolados de Curtobacterium flaccumfaciens. Summa Phytopathologica, 32 (2): 170-176. 
Souza, V. L; Maringoni, A. C. 2008. Análise ultraestrutural da interação de Curtobacterium flaccumfaciens pv. flaccumfaciens em genótipos de feijoeiro. Summa Phytopathologica, 34 (4) 318-320.

Souza, V. L.; Maringoni, A. C.; Sérgio, A. M. C.; Ito, M. F. 2006a. Resistência genética em genótipos de feijoeiro a Curtobacterium flaccumfaciens pv. flaccumfaciens. Summa Phytopathologica, 32 (4): 339-344.

Tegli, S.; Sereni, A.; Surico, G. 2002. PCR - based assay for the detection of Curtobacterium flaccumfaciens pv. flaccumfaciens in bean seeds. Letters in Applied Microbiology, 35: 331-337.

Theodoro, G. F.; Herbes, D. H.; Maringoni, A. C. 2007. Fontes de resistência à murcha de curtobacterium em cultivares locais de feijoeiro, coletadas em Santa Catarina. Ciência e Agrotecnologia, 31 (5): 333-1339.

Theodoro, G. F.; Maringoni, A. C. 2006. Effect of potassium levels in the severity of bacterial wilt in common bean cultivars. Summa Phytopathologica, 32 (2): 139-146.
Theodoro, G. F.; Maringoni, A. C.; Hemp, S. 2004. Distribuição de Curtobacterium flaccumfaciens pv. flaccumfaciens em lavouras de feijoeiro comum no estado de Santa Catarina. Fitopatologia Brasileira, 29 (Suplemento): S39.

Uesugi, C. H.; Freitas, M. A.; Menezes, J. R. 2003. Ocorrência de Curtobacterium flaccumfaciens pv. Flaccumfaciens em feijoeiro, em Goiás e no Distrito Federal. Fitopatologia Brasileira, 28 (3): 324 .

Vale, N. M.; Barili, L. D.; Rocha, F.; Rozzetto, D. S.; Pereira, T. P.; Coimbra, J. L. M.; Guidolin, A. F.; Bertoldo, J. G. 2009. Métodos de semeadura empregados como critério de avaliação fenotípica em melhoramento de feijão. Revista Biotemas, 22 (4): 73-81.

Wendland, A.; Alencar, N. A.; Melo, L. C.; Costa, J. G. C.; Del Peloso, M. J.; Pereira, H. S.; Faria, L. C.; Côrtes, M. V. C. B.; Brondani, R. P. V. 2008 Padrão de sintomas de isolados de Curtobacterium flaccumfaciens pv. flaccumfaciens em dois genótipos de feijoeiro. Embrapa Arroz e Feijão, Santo Antônio de Goiás, Brasil, 19pp. (Boletim de Pesquisa e Desenvolvimento, 33). 